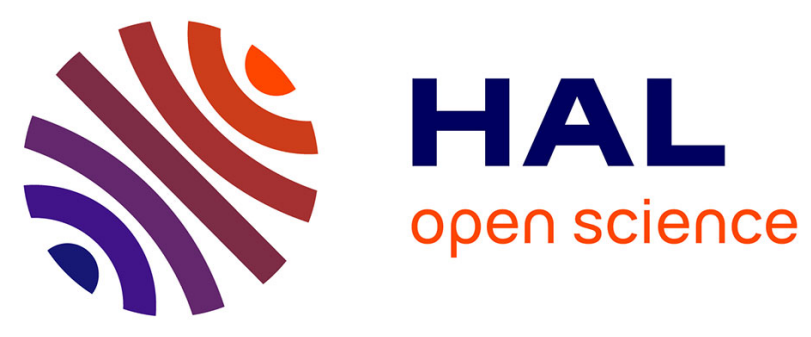

\title{
Work factors associated with return to work in out-of-hospital cardiac arrest survivors
}

\author{
Alexis Descatha, Florence Dumas, Wulfran Bougouin, Alain Cariou, \\ Guillaume Geri
}

\section{- To cite this version:}

Alexis Descatha, Florence Dumas, Wulfran Bougouin, Alain Cariou, Guillaume Geri. Work factors associated with return to work in out-of-hospital cardiac arrest survivors. Resuscitation, inPress, 128, pp.170-174. 10.1016/j.resuscitation.2018.05.021 . inserm-02468247

\section{HAL Id: inserm-02468247 https://www.hal.inserm.fr/inserm-02468247}

Submitted on 5 Feb 2020

HAL is a multi-disciplinary open access archive for the deposit and dissemination of scientific research documents, whether they are published or not. The documents may come from teaching and research institutions in France or abroad, or from public or private research centers.
L'archive ouverte pluridisciplinaire HAL, est destinée au dépôt et à la diffusion de documents scientifiques de niveau recherche, publiés ou non, émanant des établissements d'enseignement et de recherche français ou étrangers, des laboratoires publics ou privés. 


\section{Work factors associated with return to work in out-of-hospital cardiac arrest survivors}

Alexis Descatha ${ }^{1,2,3}, \mathrm{MD}, \mathrm{PhD}$, Florence Dumas ${ }^{4,5}, \mathrm{MD}, \mathrm{PhD}$, Wulfran Bougouin ${ }^{5,6}, \mathrm{MD}, \mathrm{PhD}$, Alain $\mathrm{Cariou}^{5,6}, \mathrm{MD}, \mathrm{PhD}$, and Guillaume Geri ${ }^{2,7,8}, \mathrm{MD}, \mathrm{PhD}$

1. AP-HP (Paris Hospital "Assistance Publique Hôpitaux de Paris"), Occupational Health Unit, University hospital of West Suburb of Paris, Poincaré site, Garches, France

2. Versailles St-Quentin University UVSQ - Paris Saclay University, UMS 011, UMR-S 1168, France

3. Inserm, Population-based Epidemiologic Cohorts Unit, UMS 011, Villejuif, France; Inserm, VIMA : Aging and chronic diseases. Epidemiological and public health approaches, U1168, F-94807, Villejuif, France

4. Paris Descartes University, AP-HP, Emergency Department, Cochin Hospital, APHP, France.

5. Sudden Death Expertise Centre, INSERM U970, Paris, France

6. Medical Intensive Care Unit, Cochin Hospital, APHP, Paris, France

7. Medical Intensive Care Unit, Ambroise Paré Hospital, APHP, Paris, France

8. INSERM UMR 1018, Team Heart and Kidney, CESP, Villejuif, France

Key words: out-of-hospital; cardiac arrest; return to work; long-term outcome; occupational; work

Running title: Return to work after cardiac arrest

Corresponding author: Prof A Descatha, Unité de santé professionnelle AP-HP UVSQ, CHU Poincaré, 104 bd Poincaré, 92380 Garches, France, tel +33147107764, fax +33 147107768

Mail alexis.descatha@inserm.fr

All authors have participated in the conception and design of this study, or the acquisition of data, or the analysis and interpretation of the data, drafting of the article, or revising it critically for important intellectual content, and final approval of the version submitted. 


\begin{abstract}
Introduction. Although the survival rate after out-of-hospital cardiac arrest (OHCA) has increased over time, little is known about the return to work of OHCA survivors. We aim to evaluate prevalence and factors associated with return to work (RTW) in OHCA survivors. Patients and methods. All consecutive OHCA survivors aged 18-65 years and discharged alive from a Paris tertiary intensive care unit between 2000 and 2013 were included. Pre-hospital care, in-hospital care, and after-hospital discharge data, such as work description (work location, job classification, nature of the job) were compared relative to work status and RTW. Factors associated with RTW were evaluated using multivariable logistic regression.
\end{abstract}

Results. 153 OHCA survivors were included in the analysis. Among them, 96 (62.8\%) returned to work an average of 714 days after OHCA (SD 1031); mostly to the same job $(n=72,75 \%)$. Six patients changed jobs $(4 \%)$ and 12 reduced their activity $(10.6 \%)$. Factors associated with RTW were younger age (adjusted odds ratio (aOR) 3.64 [1.10; 12.02]), being managers and professionals, and service and sales workers (compared to technicians and associate professionals, clerical support workers, respectively aOR $3.43[1.05 ; 11.22]$ and $4.69[1.14 ; 19.37])$, and workplace occurrence (aOR 11.72 [1.37; 99.93]).

Conclusion. Two thirds of OHCA survivors, in the present study, returned to work. Patients with a higher-level job, and with the arrest occurring in the workplace, were more likely to return to work. Further research should include more details of job contents, evolution, financial consequences, as well as prevention practices related to work location. 
Survival after out-of-hospital cardiac arrest (OHCA) has increased over the last few decades. ${ }^{1-4}$ There is growing interest in the specifics of qualitative survival, including healthrelated quality of life (HRQOL), of OHCA survivors. ${ }^{5-7}$ Recently, Smith et al have reported similar 12 month HRQOL between OHCA survivors and individuals from the general population. ${ }^{8}$ We observed similar results in our Parisian cohort and found that younger age and male gender were associated with better long-term HRQOL. ${ }^{9}$

Work is a major component of health and functioning. It has been found that among the OHCA survivors assumed to return to work (RTW), those with cognitive impairment were more likely to be on sick leave compared with those without cognitive impairment. ${ }^{10}$ Of 12,332 working-age patients who suffered an OHCA recorded in the Danish Cardiac Arrest Register, 796 survived and $610(76.6 \%)$ returned to work, but no details were given about the nature of the job. ${ }^{11}$ We aimed to describe the prevalence of, and factors associated with, RTW in a French cohort of OHCA survivors.

\section{Methods}

The design and inclusion criteria in the cohort have been described previously. ${ }^{9}$ In brief, all consecutive OHCA patients of our intensive care unit between 2000 and 2013 were prospectively included. Among the survivors followed, only working-age patients (18-65 years old) who had a job when the cardiac arrest occurred were included in the present study. Data of pre- and in-hospital care were recorded according to the Utstein style. ${ }^{12}$ In the present study, we focus on demographic data, cardiac arrest location, and initial Utstein variables (i.e. time from collapse to cardiopulmonary resuscitation [CPR] -"no-flow"-, time from CPR to 
restoration of spontaneous circulation [ROSC], presence of a witness, bystander CPR, and external defibrillation).

Initial job content was coded using the 2008 International Standard Classification of Occupations (ISCO-08) and recoded into four categories based on the first digits (1: managers and professionals; 2: technicians and associate professionals, clerical support workers; 3: services and sales workers ; 4: craft and related trades workers, plant and machine operators and assemblers, elementary occupations; no skilled agricultural, forestry and fishery workers were included, as expected for an urban area). ${ }^{13}$ Jobs requiring manual tasks (defined as having a combination of at least two biomechanical factors), responsibilities (defined as involving a high level of decision making), and intellectual content (defined as involving a high level of mental demand) were also coded by an occupational health specialist. OHCA occurring in a work setting was recorded as well.

RTW was evaluated by a trained clinical research assistant during standardized telephone interviews. A standardized protocol was used for follow-up, and the patient was declared lost to follow-up for interview after 3 series of 6 attempts each were performed without success. Information on the type of activity (similar, reduced), job change, or retirement was included (reduced activity was considered as RTW). Neurological performance was also evaluated using the Cerebral Performance Category $(\mathrm{CPC}),{ }^{14}$ as well as/including independence in everyday activities assessed by the Katz index for activities of daily living (ADL). ${ }^{9} \mathrm{CPC}$ scores range from 1 to 5: (1) good cerebral performance; (2) moderate cerebral disability; (3) severe cerebral disability; (4) coma or vegetative state and (5) death. In the present study, we defined good neurological performance by CPC1 and intermediate or poor neurological performance by CPC other than 1 . The ADL index ranks performance adequacy in the six functions of bathing, dressing, toilet, transferring, continence, and feeding. Participants 
reporting that they needed help with any of the activities (i.e. ADL <6) were considered to have impaired ADL.

We described OHCA characteristics according to return to work as well as type of professional activity. We then analyzed factors associated with RTW, coded yes/no, using multivariable logistic regression. The dependent variable was return to work, while independent variables included OHCA characteristics, which were associated with the main outcome in the univariate analysis having a p-value lower than or equal to 0.20 , in order to avoid having too many variables in the model. To take into account a potential period effect, we divided the study into 2 equal time periods (2000- 2006, 2007 -2013). Separate models with job content and classification were constructed to avoid over-adjustment.

The accepted level of significance was set at $\mathrm{p} \leq 0.05$ for all analyses. Statistical analyses were carried out using the Statistic Analysis Software SAS V9.4 package (SAS Institute, Inc. Cary, NC, USA). Data description was performed according to the STROBE guidelines related to observational study reporting. ${ }^{15}$ Our local ethics committee approved the study.

\section{Results}

Of 379 survivors followed, 153 were included in the study (mean follow-up 1643 days, standard deviation 1371, median 1268, interquartile range 525- 2387 range 61-4967, Figure 1). Most of them suffered OHCA after $2007(n=111,73 \%)$. Mean time from collapse to start of CPR was 3.9 (standard deviation 4.55) min and mean time from CPR to ROSC was 13.7 (SD 10.53) $\mathrm{min}$. 
Ninety-six (96) /153 (62.8\%) OHCA survivors returned to work an average of 714 (SD 1031) days after OHCA occurrence (median 241 days, interquartile range 93-911 days) and mostly

to the same job (Table 1). Retirement was more frequent in older survivors, except for manual workers. Three workers returned to work and retired a few months later, and one returned to work but suffered from myocardial infarction and stopped working 2 years later (considered here as return to work). Good neurological outcome (CPC1 n=130/89.0\% compared to CP2 $n=12 / 8.2 \%$ and CPC $3 n=4 / 2.7 \%$, no CPC4 was observed), and normal daily life autonomy were associated with RTW $(\mathrm{P}<0.0005)$.

The factors associated with return to work were younger age, being "managers and professionals" (compared to "technicians and associate professionals, clerical support workers") and workplace occurrence, as well as initial period (2000-2006 vs 2007-2013, Table 2). Work contents (manual, with responsibility, intellectual) were not significantly associated with RTW.

Workplace location was strongly associated with time from CPR to ROSC ( $<<0.001)$, but not with time from collapse to CPR, nor with other components of the chain of survival. RTW was more likely for those with a work place occurrence, although the confidence interval was very broad (table 2$)$. In total, $68 \%(n=15$ of 22$)$ of those with the OHCA occurring at the workplace were able to RTW at the same job and working level.

\section{Discussion}

In the present study, we found that about two-thirds of OHCA survivors of working age returned to work. Moreover, we observed a strong association between certain work factors, 
like workplace occurrence, and a high-position job, and the RTW of OHCA patients discharged alive from hospital.

Similar results were observed in a previously published study focusing on employment after therapeutic hypothermia based on 87 OHCA survivors: $65 \%$ of them returned to work, a rate similar to our study (62.8\%). ${ }^{16}$ Interestingly, while OHCA survival increased in the second study period (2007-2013), we observed a lower proportion of patients who returned to work in that period. These results differ from the Kragholm study, which found a more frequent RTW rate in the most recent years (i.e. 2011 vs. 2001). ${ }^{11}$ Improvement in the survival chain has led to survival improvement with the AED deployment plan in 2007, but has also increased the number of patients sent to hospital, and led to a lower proportion of long-term survival. Cultural differences in sick-leave between countries, and differences for health coverage in France are also a possible explanation. ${ }^{10}$

The notion of the workplace is heterogeneous. ${ }^{17}$ Nevertheless, workplace location might differ from the "classical" public setting defined in the Utstein style, as better survival has been shown in such a setting. ${ }^{18}$ Sasson et al. found that witnessed OHCA, shockable rhythm, and achieved return of spontaneous circulation are predictors of survival in OHCA. ${ }^{1}$ In the present study, we observed such an association especially when the probable underlying factor is a shorter time of low flow in this particular location. However, there is room for improvement, since the association of workplace location of cardiac arrest with no flow time, as well as with other components of the survival chain, were not significant. Workplace as a prognostic factor might have important consequences for prevention and return to work. ${ }^{19}$ When OHCA occurs 
in the workplace setting, it might lead to anticipation of RTW, and to analysis of the initial workplace management and the chain of survival for improvement, such as prevention of OHCA and other potential work risks.

We acknowledge several limitations in the present study. Selection effects related to the specificities of our monocentric cohort of OHCA survivors have been previously discussed, with no sociodemographic difference on followed and lost to follow-up patients. ${ }^{9}$ OHCA patients with a greater likelihood of RTW are not more likely to be referred to our center than another, and a selection effect is unlikely to have occurred, and the social distribution is similar to that of the Paris area. ${ }^{20}$ Second, we have focused on RTW ("employability") rather than time for RTW. It could indeed be argued that neurological recovery may improve over the first 12 months. However, some patients in the present analysis have changed their working status over time: 3 have retired, and one suffered from a myocardial infarction 2 years after her RTW. Last, we did not analyze the association between job content and return to work. We only observed an association between the international job classification and the main outcome, but none with the content. This may be related to the quality of data collection gathered during the telephone interview, as the interviewer did not focus on real job exposure assessment. Other aspects of the job exposure were also not analyzed here, such as the organizational or psychosocial context of work, the size of the company, and the involvement of the occupational health services. ${ }^{21}$ Thus, we could not interpret work differences in detail, and only more information about job contents from further research will allow reliable conclusions.

In conclusion, this study emphasizes the importance of studying RTW after OHCA. Further research should include more details of job contents, evolution, and financial consequences, 
as well as prevention practices related to work location, and information provided to patients about optimizing their RTW.

\section{Acknowledgements}

We would like to thank Richard Carter for helping us to improve the language of this document.

\section{References}

1. Sasson C, Rogers MAM, Dahl J, Kellermann AL. Predictors of survival from out-ofhospital cardiac arrest: a systematic review and meta-analysis. Circ Cardiovasc Qual Outcomes. 2010;3:63-81.

2. Chan PS, McNally B, Tang F, Kellermann A, CARES Surveillance Group. Recent trends in survival from out-of-hospital cardiac arrest in the United States. Circulation. 2014;130:1876-1882.

3. Wong MKY, Morrison LJ, Qiu F, Austin PC, Cheskes S, Dorian P, Scales DC, Tu JV, Verbeek PR, Wijeysundera HC, Ko DT. Trends in short- and long-term survival among out-of-hospital cardiac arrest patients alive at hospital arrival. Circulation. 2014;130:1883-1890.

4. Benjamin EJ, Blaha MJ, Chiuve SE, Cushman M, Das SR, Deo R, de Ferranti SD, Floyd J, Fornage M, Gillespie C, Isasi CR, Jiménez MC, Jordan LC, Judd SE, Lackland D, Lichtman JH, Lisabeth L, Liu S, Longenecker CT, Mackey RH, Matsushita K, Mozaffarian D, Mussolino ME, Nasir K, Neumar RW, Palaniappan L, Pandey DK, Thiagarajan RR, Reeves MJ, Ritchey M, Rodriguez CJ, Roth GA, Rosamond WD, Sasson C, Towfighi A, Tsao CW, Turner MB, Virani SS, Voeks JH, Willey JZ, Wilkins JT, Wu JH, Alger HM, Wong SS, Muntner P, American Heart Association Statistics Committee and Stroke Statistics Subcommittee. Heart Disease and Stroke Statistics-2017 Update: A Report From the American Heart Association. Circulation. 2017;135:e146-e603.

5. Sunnerhagen KS, Johansson O, Herlitz J, Grimby G. Life after cardiac arrest; a retrospective study. Resuscitation. 1996;31:135-140.

6. Stiell I, Nichol G, Wells G, De M, Nesbitt L, Blackburn J, Spaite D. Health-related quality of life is better for cardiac arrest survivors who received citizen cardiopulmonary resuscitation. Circulation. 2003;108:1939-1944. 
7. Larsson I-M, Wallin E, Rubertsson S, Kristofferzon M-L. Health-related quality of life improves during the first six months after cardiac arrest and hypothermia treatment. Resuscitation. 2014;85:215-220.

8. Smith K, Andrew E, Lijovic M, Nehme Z, Bernard S. Quality of life and functional outcomes 12 months after out-of-hospital cardiac arrest. Circulation. 2015;131:174-181.

9. Geri G, Dumas F, Bonnetain F, Bougouin W, Champigneulle B, Arnaout M, Carli P, Marijon E, Varenne O, Mira J-P, Empana J-P, Cariou A. Predictors of long-term functional outcome and health-related quality of life after out-of-hospital cardiac arrest. Resuscitation. 2017;113:77-82.

10. Lilja G, Nielsen N, Bro-Jeppesen J, Dunford H, Friberg H, Hofgren C, Horn J, Insorsi A, Kjaergaard J, Nilsson F, Pelosi P, Winters T, Wise MP, Cronberg T. Return to Work and Participation in Society After Out-of-Hospital Cardiac Arrest. Circ Cardiovasc Qual Outcomes. 2018;11:e003566.

11. Kragholm K, Wissenberg M, Mortensen RN, Fonager K, Jensen SE, Rajan S, Lippert FK, Christensen EF, Hansen PA, Lang-Jensen T, Hendriksen OM, Kober L, Gislason G, TorpPedersen C, Rasmussen BS. Return to Work in Out-of-Hospital Cardiac Arrest Survivors: A Nationwide Register-Based Follow-Up Study. Circulation. 2015;131:1682-1690.

12. Jacobs I, Nadkarni V, Bahr J, Berg RA, Billi JE, Bossaert L, Cassan P, Coovadia A, D'Este K, Finn J, Halperin H, Handley A, Herlitz J, Hickey R, Idris A, Kloeck W, Larkin GL, Mancini ME, Mason P, Mears G, Monsieurs K, Montgomery W, Morley P, Nichol G, Nolan J, Okada K, Perlman J, Shuster M, Steen PA, Sterz F, Tibballs J, Timerman S, Truitt T, Zideman D. Cardiac arrest and cardiopulmonary resuscitation outcome reports: update and simplification of the Utstein templates for resuscitation registries: a statement for healthcare professionals from a task force of the International Liaison Committee on Resuscitation (American Heart Association, European Resuscitation Council, Australian Resuscitation Council, New Zealand Resuscitation Council, Heart and Stroke Foundation of Canada, InterAmerican Heart Foundation, Resuscitation Councils of Southern Africa). Circulation. 2004;110:3385-3397.

13. ISCO - International Standard Classification of Occupations [Internet]. [cited $2018 \mathrm{Mar}$ 25];Available from: http://www.ilo.org/public/english/bureau/stat/isco/isco08/

14. A randomized clinical study of cardiopulmonary-cerebral resuscitation: design, methods, and patient characteristics. Brain Resuscitation Clinical Trial I Study Group. Am J Emerg Med. 1986;4:72-86.

15. von Elm E, Altman DG, Egger M, Pocock SJ, Gotzsche PC, Vandenbroucke JP. The Strengthening the Reporting of Observational Studies in Epidemiology (STROBE) statement: guidelines for reporting observational studies. PLoSMed. 2007;4:e296.

16. Kragholm K, Skovmoeller M, Christensen AL, Fonager K, Tilsted H-H, Kirkegaard H, DE Haas I, Rasmussen BS. Employment status 1 year after out-of-hospital cardiac arrest in comatose patients treated with therapeutic hypothermia. Acta Anaesthesiol Scand. 2013;57:936-943. 
17. Palaghita A, Jost D, Despreaux T, Bougouin W, Beganton F, Loeb T, Tourtier JP, Descatha A. Characteristics of Cardiac Arrest Occurring in the Workplace: A Post Hoc Analysis of the Paris Area Fire Brigade Registry. J Occup Environ Med. 2016;

18. Descatha A, Dagrenat C, Cassan P, Jost D, Loeb T, Baer M. Cardiac arrest in the workplace and its outcome: a systematic review and meta-analysis. Resuscitation. 2015;

19. American College of Occupational and Environmental Medicine (ACOEM). Position Statement $\mid$ Automated External Defibrillation in the Occupational Setting (reaffirmed May 2006) [Internet]. [cited 2012 Feb 17];Available from:

http://www.acoem.org/AED_OccupationalSetting.aspx

20. Les catégories sociales dans les départements [Internet]. Observatoire des inégalités. [cited 2018 Apr 8];Available from:

https://www.inegalites.fr/spip.php?id_article=697\&page=article

21. Descatha A, Baer M. Automated external defibrillators in the workplace. $B M J$. 2008;337:a1816. 
Table 1. Description between work status and relevant variables (sociodemographic, Utstein, work, period)

\begin{tabular}{|c|c|c|c|c|c|c|c|}
\hline variable & $\begin{array}{c}\text { Not at work (and } \\
\text { not retire) } \\
\mathrm{N}=47(31.3 \%) \\
\end{array}$ & $\begin{array}{c}\text { Retire } \\
\mathrm{N}=10(6.2 \%) \\
\end{array}$ & $\begin{array}{c}\text { At work. same } \\
\text { job } \\
\mathrm{N}=72(47.7 \%) \\
\end{array}$ & $\begin{array}{c}\text { At work. reduce } \\
\text { activity } \\
\mathrm{N}=16(\mathbf{1 0 . 6 \% )} \\
\end{array}$ & $\begin{array}{c}\text { At work. different } \\
\text { job } \\
\mathrm{N}=6(4.0 \%) \\
\end{array}$ & $\begin{array}{c}\text { Total } \\
\mathrm{N}=153(100 \%) \\
\end{array}$ & \\
\hline \multicolumn{8}{|l|}{ Sex } \\
\hline Men & $40(85.11 \%)$ & $8(80.00 \%)$ & $60(83.33 \%)$ & $12(75.00 \%)$ & $5(83.33 \%)$ & $126(82.35 \%)$ & . \\
\hline Women & $7(14.89 \%)$ & $2(20.00 \%)$ & $12(16.67 \%)$ & $4(25.00 \%)$ & $1(16.67 \%)$ & $27(17.65 \%)$ & . \\
\hline Age (yrs) & & & & & & & $0.023 *$ \\
\hline$<45$ & $8(17.02 \%)$ & & $25(34.72 \%)$ & $9(56.25 \%)$ & $4(66.67 \%)$ & $48(31.37 \%)$ & . \\
\hline $45-55$ & $23(48.94 \%)$ & $1(10.00 \%)$ & $24(33.33 \%)$ & $6(37.50 \%)$ & $1(16.67 \%)$ & $55(35.95 \%)$ & . \\
\hline$\geq 55$ & $16(34.04 \%)$ & $9(90.00 \%)$ & $23(31.94 \%)$ & $1(6.25 \%)$ & $1(16.67 \%)$ & $50(32.68 \%)$ & . \\
\hline \multicolumn{8}{|l|}{ Bystander on scene } \\
\hline No & $2(4.26 \%)$ & & $2(2.78 \%)$ & & & $4(2.61 \%)$ & . \\
\hline Yes & $44(93.62 \%)$ & $10(100.0 \%)$ & $68(94.44 \%)$ & $16(100.0 \%)$ & $5(83.33 \%)$ & $144(94.12 \%)$ & . \\
\hline \multicolumn{8}{|l|}{$\begin{array}{l}\text { CPR initiated by } \\
\text { bystanders? }\end{array}$} \\
\hline No & $17(36.17 \%)$ & $4(40.00 \%)$ & $27(37.50 \%)$ & $9(56.25 \%)$ & $2(33.33 \%)$ & $60(39.22 \%)$ & . \\
\hline Yes & $27(57.45 \%)$ & $6(60.00 \%)$ & $43(59.72 \%)$ & $7(43.75 \%)$ & $4(66.67 \%)$ & $88(57.52 \%)$ & . \\
\hline \multicolumn{8}{|l|}{ Shockable rhythm } \\
\hline No & $11(23.40 \%)$ & $1(10.00 \%)$ & $5(6.94 \%)$ & $3(18.75 \%)$ & & $20(13.07 \%)$ & . \\
\hline Yes & $36(76.60 \%)$ & $9(90.00 \%)$ & $67(93.06 \%)$ & $13(81.25 \%)$ & $6(100.0 \%)$ & $133(86.93 \%)$ & . \\
\hline \multicolumn{8}{|l|}{ Cardiac cause? } \\
\hline No & $11(23.40 \%)$ & $1(10.00 \%)$ & $8(11.11 \%)$ & $4(25.00 \%)$ & & $24(15.69 \%)$ & . \\
\hline Yes & $35(74.47 \%)$ & $9(90.00 \%)$ & $62(86.11 \%)$ & $11(68.75 \%)$ & $5(83.33 \%)$ & $123(80.39 \%)$ & . \\
\hline \multicolumn{8}{|l|}{$\begin{array}{l}\text { Workplace } \\
\text { occurrence }\end{array}$} \\
\hline No & $43(91.49 \%)$ & $10(100.0 \%)$ & $57(79.17 \%)$ & $12(75.00 \%)$ & $4(66.67 \%)$ & $128(83.66 \%)$ & . \\
\hline Yes & $1(2.13 \%)$ & & $15(20.83 \%)$ & $4(25.00 \%)$ & $2(33.33 \%)$ & $22(14.38 \%)$ & . \\
\hline \multicolumn{8}{|l|}{ Job classification** } \\
\hline 1 & $15(31.91 \%)$ & $2(20.00 \%)$ & $35(48.61 \%)$ & $8(50.00 \%)$ & $3(50.00 \%)$ & $65(42.48 \%)$ & . \\
\hline 2 & $11(23.40 \%)$ & $4(40.00 \%)$ & $13(18.06 \%)$ & & $1(16.67 \%)$ & $29(18.95 \%)$ & . \\
\hline 3 & $3(6.38 \%)$ & $3(30.00 \%)$ & $14(19.44 \%)$ & $5(31.25 \%)$ & $1(16.67 \%)$ & $26(16.99 \%)$ & . \\
\hline 4 & $17(36.17 \%)$ & $1(10.00 \%)$ & $10(13.89 \%)$ & $3(18.75 \%)$ & $1(16.67 \%)$ & $32(20.92 \%)$ & . \\
\hline \multicolumn{8}{|l|}{ Manual work } \\
\hline No & $23(48.94 \%)$ & $6(60.00 \%)$ & $49(68.06 \%)$ & $9(56.25 \%)$ & $2(33.33 \%)$ & $90(58.82 \%)$ & . \\
\hline Yes & $24(51.06 \%)$ & $4(40.00 \%)$ & $23(31.94 \%)$ & $7(43.75 \%)$ & $4(66.67 \%)$ & $63(41.18 \%)$ & . \\
\hline \multicolumn{8}{|l|}{ Rsponsability work? } \\
\hline No & $26(55.32 \%)$ & $5(50.00 \%)$ & $33(45.83 \%)$ & $8(50.00 \%)$ & $5(83.33 \%)$ & $77(50.33 \%)$ & . \\
\hline Yes & $21(44.68 \%)$ & $5(50.00 \%)$ & $39(54.17 \%)$ & $8(50.00 \%)$ & $1(16.67 \%)$ & $76(49.67 \%)$ & . \\
\hline \multicolumn{8}{|l|}{ Intellectual work? } \\
\hline No & $24(51.06 \%)$ & $4(40.00 \%)$ & $29(40.28 \%)$ & $8(50.00 \%)$ & $3(50.00 \%)$ & $68(44.44 \%)$ & . \\
\hline Yes & $23(48.94 \%)$ & $6(60.00 \%)$ & $43(59.72 \%)$ & $8(50.00 \%)$ & $3(50.00 \%)$ & $85(55.56 \%)$ & . \\
\hline \multicolumn{8}{|l|}{ Year } \\
\hline $2000-6$ & $4(8.51 \%)$ & $4(40.00 \%)$ & $26(36.11 \%)$ & $5(31.25 \%)$ & $2(33.33 \%)$ & $41(26.80 \%)$ & . \\
\hline $2007-13$ & $43(91.49 \%)$ & $6(60.00 \%)$ & $46(63.89 \%)$ & $11(68.75 \%)$ & $4(66.67 \%)$ & $112(73.20 \%)$ & . \\
\hline
\end{tabular}

$\mathrm{CPR}=$ cardio pulmonary resuscitation $* \mathrm{P}<0.05 * *$ Initial job content was coded using 2008 International Standard Classification of Occupations (ISCO-08) and recoded into four categories based on the first digits 1: managers and professionals; 2: technicians and associate professionals, clerical support workers; 3 : services and sales workers ; 4: craft 
and related trades workers, plant and machine operators and assemblers, elementary occupations. Missing data are not showed. 
Table 2. Association between return-to-work and relevant variables (sociodemographic, Utstein, work, period)

\begin{tabular}{|c|c|c|c|c|c|}
\hline & & $\mathbf{N}$ & n of RTW & $\%$ & OR crude \\
\hline \multicolumn{6}{|l|}{ Sex } \\
\hline & Men & 126 & 78 & 61.9 & 1 \\
\hline & Women & 27 & 18 & 66.67 & $1.23[0.51 ; 2.96]$ \\
\hline \multicolumn{6}{|l|}{ Age (yrs) } \\
\hline & $<45$ & 48 & 40 & 83.33 & $3.87[1.53 ; 9.79]$ \\
\hline & $45-55$ & 55 & 31 & 56.36 & 1 \\
\hline & $\geq 55$ & 50 & 25 & 50 & $0.77[0.36 ; 1.67]$ \\
\hline
\end{tabular}

Bystander on

scene

$\begin{array}{lll}2 & 50 & 1\end{array}$

$90 \quad 62.5 \quad 1.67[0.23 ; 12.18]$

CPR initiated by bystanders?

$\begin{array}{rrrrl}\text { No } & 60 & 39 & 65 & 1 \\ \text { Yes } & 88 & 55 & 62.5 & 0.90[0.45 ; 1.78]\end{array}$

Shockable rhythm

$\begin{array}{rrrrl}\text { No } & 20 & 8 & 40 & 1 \\ \text { Yes } & 133 & 88 & 66.17 & 2.93[1.12 ; 7.69]\end{array}$

Cardiac cause?

$\begin{array}{rr}\text { No } & 24 \\ \text { Yes } & 123\end{array}$

Workplace occurrence

$\begin{array}{rr}\text { No } & 128 \\ \text { Yes } & 22\end{array}$

\section{Job}

classification**

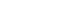

$\begin{array}{cc}1 & 65 \\ 2 & 29 \\ 3 & 26 \\ 4 & 32\end{array}$

Manual work

No $\quad 90$

Yes 63

Rsponsability

work?

$\begin{array}{lrr}\text { work? } & \text { No } & 77 \\ & \text { Yes } & 76 \\ \begin{array}{l}\text { Intellectual } \\ \text { work? }\end{array} & & \\ & \text { No } & 68 \\ & \text { Yes } & 85\end{array}$

Year

$$
\begin{array}{lrl}
12 & 50 & 1 \\
79 & 64.23 & 1.80[0.74 ; 4.33]
\end{array}
$$

$\begin{array}{lll}75 & 58.59 & 1\end{array}$

$21 \quad 95.4514 .84[1.94 ; 113.75]$

$48 \quad 73.85 \quad 3.03[1.21 ; 7.55]$

$14 \quad 48.28 \quad 1$

$14 \quad 43.75 \quad 0.83[0.30 ; 2.29]$

$\begin{array}{lll}61 & 67.78 \quad 1\end{array}$

$35 \quad 55.56 \quad 0.59[0.31 ; 1.16]$

$\begin{array}{lll}46 & 59.74 & 1\end{array}$

$50 \quad 65.79 \quad 1.30[0.67 ; 2.50]$

$\begin{array}{lll}40 & 58.82 & 1\end{array}$

$56 \quad 65.88 \quad 1.35[0.70 ; 2.61]$
$20 \quad 76.92 \quad 3.57[1.11 ; 11.48]$

$\begin{array}{cc}\mathbf{p =} & {\text { OR } \text { ajusted }^{\mathbf{1}}}^{0.6427} \\ & 1 \\ & 1.23[0.34 ; 4.52]\end{array}$

$0.0025 *$

$3.64[1.10 ; 12.02]$

1

$0.53[0.20 ; 1.41]$

0.6147

$0.0053^{*}$

$1.16[0.09 ; 15.38]$

0.7565

$$
\text { . } 1.20[0.48 ; 2.98]
$$

$0.0287^{*}$

1

2.14 [0.54; 8.54]

0.1929

$$
1
$$

$1.59[0.42 ; 5.97]$

$0.0094^{*}$

1

11.72 [ $1.37 ; 99.93$ ]

.

$3.43[1.05 ; 11.22]$

1

$4.69[1.14 ; 19.37]$

$0.89[0.24 ; 3.27]$

0.1251$$
\text { (1) }
$$$$
0.4394
$$

0.3701

$1.15[0.39 ; 3.41]$

$1.06[0.33 ; 3.43]$

$0.0077^{*}$

\begin{tabular}{|c|c|}
\hline$p=$ & OR ajusted \\
\hline 0.7519 & \\
\hline & {$[0.47 ; 5.32]$} \\
\hline
\end{tabular}

$0.0409 *$

1

$0.31[0.12 ; 0.83]$

$0.0072 *$

$3.56[1.13 ; 11.19]$

0.64 [0.25; 1.63$]$

0.9123

1

$0.70[0.05 ; 9.96]$

0.6922

1

$1.29[0.53 ; 3.15]$

0.281

1

$3.32[0.90 ; 12.25]$

$1.45[0.42 ; 5.00]$

$12.66[1.41 ; 113.53]$

$0.0201 *$

1

$0.72[0.24 ; 2.18]$

1

$0.34[0.12 ; 0.96]$
0.0

0

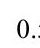

0.0

0

0.

0.0

$\mathrm{N}=$ total number, $\mathrm{n}$ of $\mathrm{RTW}=$ number of return-to-work $\mathrm{OR}=$ odds ratio $\mathrm{CPR}=$ cardio pulmonary resuscitation ${ }^{1}$ All variables included in the model are showed $* \mathrm{P}<0.05 * *$ Initial job content was coded using 2008 International Standard Classification of Occupations (ISCO-08) and 
recoded into four categories based on the first digits 1: managers and professionals; 2: technicians and associate professionals, clerical support workers; 3 : services and sales workers ; 4: craft and related trades workers, plant and machine operators and assemblers, elementary occupations. Missing data are not showed. 
Figure 1. Flow chart.

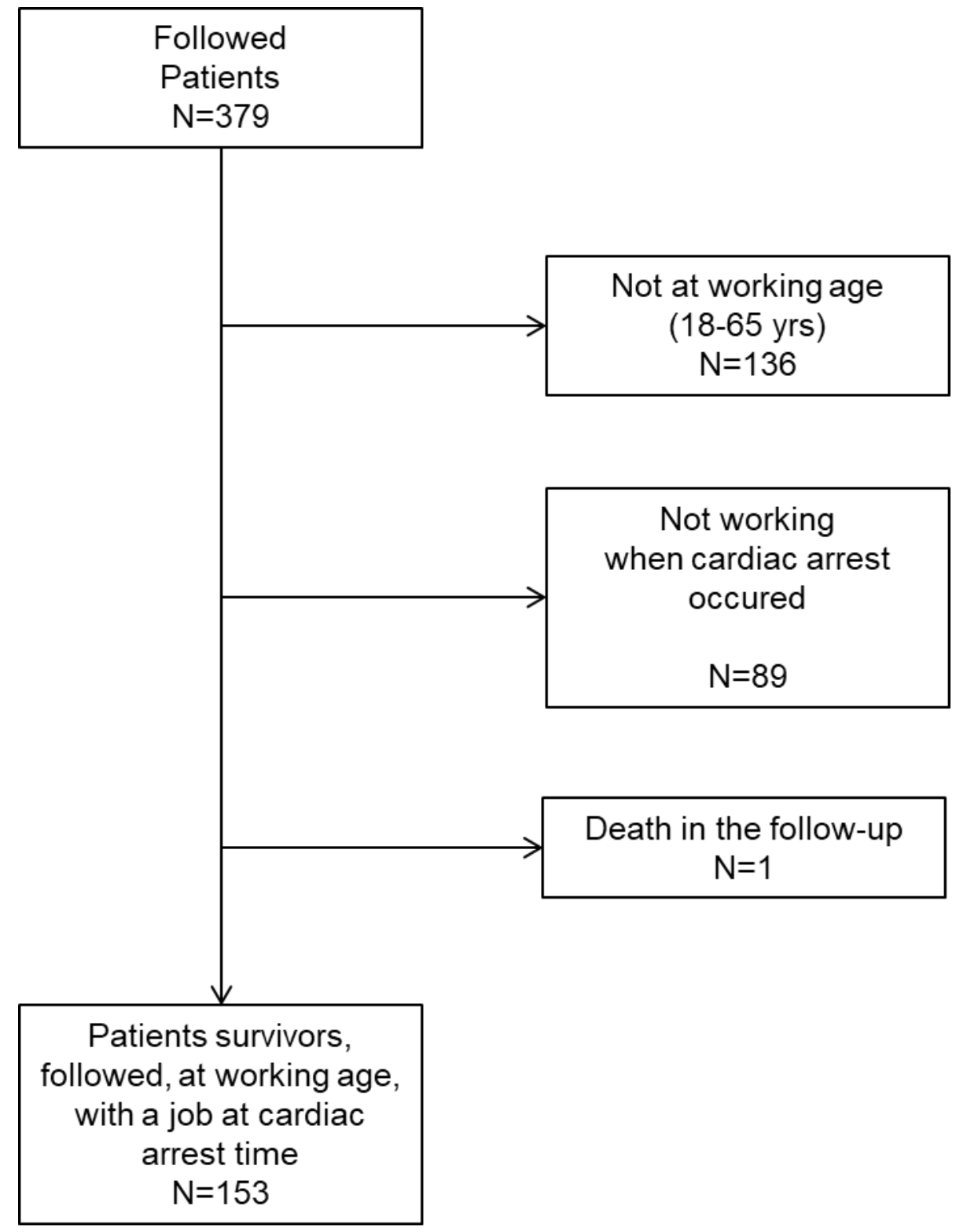

